\title{
Liberal Education and General Education in American Universities
}

\author{
Ziwei Jiang \\ Lingnan Normal University, Zhanjiang, China \\ Email: jiangziwei.yes@foxmail.com
}

How to cite this paper: Jiang, Z. W. (2019). Liberal Education and General Education in American Universities. Creative Education, 10, 1628-1634.

https://doi.org/10.4236/ce.2019.107116

Received: May 17, 2019

Accepted: July 23, 2019

Published: July 26, 2019

Copyright $\odot 2019$ by author(s) and Scientific Research Publishing Inc. This work is licensed under the Creative Commons Attribution International License (CC BY 4.0).

http://creativecommons.org/licenses/by/4.0/

\section{(c) (i) Open Access}

\begin{abstract}
Starting from the two levels of educational concept and content, this paper studies the generation, change, basic characteristics and development trend of American university liberal education and general education in recent years. Since the 17th century, the development of liberal education and general education has roughly presented four different stages of development. Since the 1990s, although there are still differences between liberal education and general education in terms of concept and curriculum, there are more and more commonalities between them than before World War II, and the integration with professional education is gradually strengthened. Absorbing practical and practical content, laying more emphasis on imparting basic knowledge and basic abilities, serving professional education, constitutes an important part of undergraduate education in the United States. This paper discusses the timeline of general education and liberal education in the United States, mainly including its emergence, development and improvement, and explores the similarities and differences between liberal education and general education. Finally, it summarizes and puts forward enlightenment.
\end{abstract}

\section{Keywords}

Liberal Education, General Education, Educational Integration

\section{Introduction}

Since the late 1990s, as an important part of undergraduate curriculum and teaching reform, general education has become popular in China (Quan, 2017). In this process, both the government and universities actively explore and develop a general education model suitable for China's national conditions, while referring to foreign experience. Compared with other countries and regions, liberal education and general education in American universities have a more im- 
portant and direct impact on domestic reforms at the conceptual and curriculum levels.

If we do not understand the impact of American liberal education on general education and the relationship between them and their changes, it will be difficult to grasp the nature of American undergraduate education, especially today's general education in the United States, and the background and characteristics of the reform of general education in some domestic universities (Wang, 2008). This paper mainly discusses how liberal education and general education come into being and change in American higher education from a historical point of view. Firstly, the article sorts out the relevant concepts; on this basis, it combs the characteristics of the emergence, development and change stages and different stages of liberal education and general education in American universities; finally, it summarizes the research findings and puts forward relevant enlightenments.

From the etymological point of view, the English general education and liberal education or liberal arts education originally came from the word cultural animi used by Cicero, an ancient Roman scholar, which meant "spiritual enlightenment".

Therefore, liberal education has a certain relationship with today's free education, education, liberal education or general spiritual cultivation. From ancient Rome, the spiritual education was called liberal art and liberal education. In addition, as far as the object of education is concerned, in ancient Greece and Rome, liberal education specifically refers to the education provided for the free people. Slaves cannot enjoy such education, so they also have a strong class character. As mentioned later, liberal education in Europe spread to the United States in the 17th century and became the core model of American colonial universities. General education did not appear in the United States until the 19th century (Zhu, 2005).

It is generally believed that liberal education, liberal studies or liberal arts education in Chinese are translated from English, while general education, General Studies and so on. After World War II, Japan introduced general education in the United States to translate it into general education, and after 1991, liberal arts education was translated into education ( $\mathrm{Lu} \& \mathrm{Gao}, 2012)$. In the 1950s, under the influence of American liberal education and general education, many colleges and universities in Hong Kong began to implement general education and liberal education. Almost at the same time, some universities in Taiwan have begun to study in the United States, promoting general education, liberal education and general education.

\section{Development of Liberal Education and General Education}

\subsection{Changes in Free Education}

Li Bo draws lessons from the experience of general education in American universities. The reform of general education curriculum in Chinese universities 
should attach importance to the importance of general education curriculum, clarify the objectives and requirements of general education curriculum training, improve the curriculum structure of general education, improve the teaching quality of general education curriculum, and reform the evaluation model of general education curriculum (Zhao, 2015). Gu Jianchun, Pan Wenli explored the goal, curriculum and evaluation reform trend of integration of general education and professional education in famous American universities, hoping to provide a reference for higher education reform in China (Huang \& Meng, 2011). Paul-Redsell, in his book College and University Courses published in 1968, made a detailed study of the reform of American liberal education from the second half of the 1950s to the 1960s. According to the book, at the University level, the changes in the content of free education include the following two aspects (Gu \& Pan, 2008).

The first aspect is to develop a wide range of curriculum content. 1) Developing students' autonomous learning subjects or teaching methods. For example, under the guidance of teachers, students read designated documents, engage in research projects, cultivate and improve oral expression and writing skills, and the ability to find and solve problems. 2) Arrange students from different subjects or backgrounds together to offer a unified seminar. In this way, students can not only broaden their horizons of learning and strengthen their depth of learning, but also avoid the phenomenon of too narrow learning content caused by students majoring in different courses. 3) Creating a learning environment for learning. By improving the living and learning environment and developing the corresponding learning content, the consistency and integrity of students' knowledge can be guaranteed. For example, students from different cultural backgrounds live together, and build communities where students and faculty and university administrators can communicate and communicate. 4) To provide students with short-term overseas study or experience as well as study and research.

Secondly, let students understand and master the work and service experience. Specifically, it includes the following contents (Li, 2008): 1) Developing curriculum content that can combine work with university learning. For example, through short-term probation in enterprises, factories and government agencies, students can understand and familiarize themselves with the new environment different from universities, experience and master the new contents which are helpful to university learning. 2) Accumulate the experience of the society, especially the community. During the study period, students use summer vacation to provide services for community residents, to serve as consultants, or to participate in relevant topics of their community enterprises and government agencies (O’Banion \& Terry, 2016).

The reform of free education is not limited to the renewal of some contents or the reduction of teaching contents. The overall structure of free education, the relationship between teachers and students, and the teaching methods have also changed significantly (Charley, 2015). According to the research of Carlo 
Schneider and Robert Seanberg, these changes are mainly manifested in the following aspects: emphasizing the acquisition of knowledge skills or abilities, understanding various knowledge-seeking patterns, developing knowledge about society, citizens and the world, self-knowledge and acquisition of basic knowledge, emphasizing the concentration and integration of knowledge. In terms of teacher-student relationship, teachers are no longer in an authoritative position as they used to be. They mainly impart knowledge to students unilaterally through classroom lectures or small-scale discussion classes. Teachers gradually play the role of guides, mainly to provide students with learning suggestions. In addition, one of the biggest changes in teaching methods is the development of computer-based teaching methods in the process of free education, in which students become the main body of learning (Bosch, 2016).

\subsection{Changes in General Education}

In 2000, Jerry Gaff summarized the major changes in general education curriculum in the United States from the 1980s to the 1990s as follows (Kochharlindgren, 2015).

Humanities and science not only gradually occupy a prominent position in general education, but also strengthen the connection between general education and professional education because professional education has been paid more attention than before; Emphasis should be placed on the cultivation of basic skills centered on writing or conversational skills, critical thinking skills, foreign language skills, mathematics and computer skills; Setting stricter standards for enrollment and graduation; Reduce the number of selected subjects, increase compulsory subjects, and strive to achieve structured curriculum to ensure that students meet the lowest academic standards; Improve the "freshman" education, by offering seminars or introductory courses on different topics, lay a good foundation for students to enter the senior courses smoothly; Strengthen senior education, through research projects, works creation, off-campus enterprises and other internships, to promote students to apply the knowledge to practice, to provide students with certain conditions to give full play to their abilities; Enriching the content of global learning; Through core courses, it provides information on race, social class and gender in American and Western traditions; Developing different subjects or interdisciplinary courses; Through offering courses on professional ethics, social problems and the impact of scientific and technological progress on society, we should strengthen the education of students' values; Implementing 4-year consistent general education; Emphasis should be placed on students' active learning, and the quality of education should be continuously improved through the implementation of student effectiveness evaluation (Lyons, Huber, Carter et al., 2016).

Since the beginning of the 21st century, Harvard University has also reformed its general education. By 2009, Harvard University has formulated four major objectives of general education: Firstly, prepare students for participating in civic activities; secondly, educate students to realize that they are the traditional 
products of art, thought and various values, and are also successors; thirdly, students should be able to respond to changes critically and constructively; fourthly, make students understand and realize the importance of ethical results brought about by their words and deeds (Mcilhenny, Kurashima, Chan et al., 2017). To achieve these goals, Harvard University offers the following eight general education courses: understanding of aesthetics and hermeneutics, culture and beliefs, empirical and mathematical reasoning, ethical reasoning, science of biological systems, science of the physical universe, global society, and the United States in the world. In terms of students' learning style, we should change the core curriculum model that has been implemented for many years and implement restrictive elective courses. According to the regulations of the school, students take a certain proportion of credits from each of the above eight major courses.

\subsection{Difference and Relevance between Liberal Education and General Education}

As for the difference and connection between liberal education and general education, the author interviewed Gaff, former president of the All-American College and University Association, in September 2009. He believed that the concept of free education appeared earlier than the concept of general education, but in recent years, the difference between them has become increasingly blurred. Many universities use these two concepts according to their own understanding. Historically, there are obvious differences in educational purposes, educational objects and curriculum contents between the two. Since the beginning of the 21st century, there have been more and more similarities between the two. For example, in order to train students to better face and cope with the complex and changing society in the future, on the one hand, they provide students with a wide range of scientific or cultural, as well as social knowledge; on the other hand, they teach students to master more profound knowledge in specific fields. In addition, both of them are expected to provide relevant teaching content to help students have a sense of social responsibility, master transferable knowledge and skills, and practical ability. These skills or abilities include communication, analysis, problem solving, and the ability to apply acquired knowledge and skills to the field and society.

The continuous change of the connotation and extension of free education can be clearly reflected from the definition of free education on the homepage of all American colleges and universities association. For example, according to the Association's latest definition of free education, "free education provides students with a wide range of knowledge in the world (such as science, culture and society) and profound learning content in specific fields". Free education helps students develop a sense of social responsibility, solid and transferable academic and practical skills, such as the ability to communicate, analyze and solve problems, and the ability to apply knowledge and ability to the real world. Today, liberal education usually includes general education courses, which mainly provide broad knowledge in multi-disciplines and more profound learning content 
in a major.

Thus, in recent years, although some scholars, universities or professional academic groups still use liberal education and general education differently, at least at the conceptual and curriculum level, compared with pre-World War II, especially before the 19th century, the differences between liberal education and general education in the United States are obviously decreasing, showing a trend of integration and infiltration.

\section{Conclusion}

As a result of adapting to the needs of the local environment and social changes in the United States, general education, though appearing later than liberal education, has exerted an increasing influence on undergraduate education in the United States and even overseas since the 1960s by accepting more educates, developing teaching contents more in line with the social development of the United States, and strengthening the integration with professional education or majors. However, it is worth emphasizing that, nowadays, because the liberal education and general education in American universities are basically in the same direction of reform, the differences between them are gradually blurred, showing a trend of mutual absorption and integration.

\section{Conflicts of Interest}

The author declares no conflicts of interest regarding the publication of this paper.

\section{References}

Bosch, M. E. (2016). Examining the Attitudes of Secondary General Education and Special Education Teachers toward Inclusion of Children with Autism in General Education Classrooms. Journal of the American Academy of Special Education Professionals, 10, 693-700.

Charley, C. Y. (2015). General Education and Special Education Teachers' Attitudes toward Inclusion. Dissertations \& Theses.

Gu, J., \& Pan, W. (2008). Research on the Integration of General Education and Professional Education in Famous American Universities. Heilongjiang Higher Education Research, No. 5, 78-80.

Huang, M., \& Meng, K. (2011). Enlightenment of American Independent and Free Education Model on Innovative Training of Chinese College Students. China Science and Technology Information, No. 4, 222-223.

Kochharlindgren, G. (2015). Transformative General Education across Asia. In United Christian Board Conference of Asian Scholars (pp. 67-72).

Li, B. (2008). Experience and Enlightenment of American General Education Curriculum Reform. Journal of Linyi University, 30, 47-50.

Lu, Y., \& Gao, T. (2012). Experience and Enlightenment of General Education Course in American Universities. Continuing Education Research, No. 10, 189-190.

Lyons, G. L., Huber, H. B., Carter, E. W. et al. (2016). Assessing the Social Skills and Problem Behaviors of Adolescents with Severe Disabilities Enrolled in General Educa- 
tion Classes. American Journal on Intellectual \& Developmental Disabilities, 121, 327. https://doi.org/10.1352/1944-7558-121.4.327

Mcilhenny, C., Kurashima, Y., Chan, C. et al. (2017). General Surgery Education across Three Continents. The American Journal of Surgery, 215, 209-213.

O’Banion, T. (2016). A Brief History of General Education. Community College Journal of Research and Practice, 40, 327-334. https://doi.org/10.1080/10668926.2015.1117996

Quan, J. (2017). General Education Model and Its Significance in American Universities. Continuing Education Research, No. 4, 118-120.

Wang, Y. (2008). Recessive Education in General Education in American Universities and Its Enlightenment. Changchun: Northeast Normal University.

Zhao, N. (2015). On the Characteristics and Enlightenment of Free Education in American Colleges and Universities. Journal of Liaoning Radio and Television University, No. 1, 19-21.

Zhu, X. (2005). Idea Analysis of General Education in American Universities. Journal of Inner Mongolia Normal University: Educational Science Edition, No. 1, 5-8. 